\title{
ПРОМЫШЛЕННОСТЬ ВТОРИЧНОЙ ПЕРЕРАБОТКИ: ЭКОНОМИКА ПАН-ЕВРОПЕЙСКОГО СЕКТОРА
}

\author{
(c) 2020 Алексеев Андрей Алексеевич \\ доктор экономических наук, профессор \\ Санкт-Петербургский государственный экономический университет, Россия, Санкт-Петербург \\ E-mail: idc@unecon.ru \\ (C) 2020 Фомин Евгений Пименович \\ доктор экономических наук, профессор, заведующий кафедрой налогообложения и аудита \\ Самарский государственный экономический университет, Россия, Самара \\ E-mail: fomin@sseu.ru \\ (c) 2020 Фомина Наталья Евгеньевна \\ доктор экономических наук, доцент, \\ генеральный директор, АО «Объединенная спичечная компания», Россия, Санкт-Петербург \\ E-mail: natalia.fomina@mail.ru
}

(c) 2020 Титов Антон Борисович

доктор экономических наук, профессор, проектор

АНОО «Водная академия», Россия, Санкт-Петербург

E-mail: titovanton@bk.ru

В настоящей публикации представлены результаты статистического исследования финансовых показателей пан-европейской промышленности вторичной переработки. Исследование проведено в рамках дилеммы об институциональной принадлежности, стейкхолдерах системы вторичного обращения: экологическая функция противопоставляется предпринимательской. Выделены и описаны основные сегменты промышленности вторичной переработки, классифицируемые по результативности и эффективности операционной деятельности. Представляемые результаты исследования являются актуализацией вопроса об экономике промышленности переработки вторичного сырья, рассмотренные в публикациях (2011-2014 года) гранта Waste Management SE-500.

Ключевые слова: экономика замкнутого цикла, вторичная переработка, строительство, инновации, предпринимательство, промышленность

\section{Введение}

Мировоззренческая парадигма «устойчивого развития» нашла воплощение в экономических концепциях, в первую очередь в «экономике замкнутого цикла», противопоставляемой «линейной» (Еврокомиссия [1]). Регенеративный характер (Proost J. [2]) экономики замкнутого цикла (также встречается в текстах: «циклическая», «циркуляционная», от англ. circular economy) выражается в принятии отходов производства и потребления как вторичного сырья, циркуляция которых обеспечивает рост объема ресурсов промышленности и устойчивость природопользования субъектами экономической и социальной деятельности. В экономической проекции концепция рассматривается на макрои микроуровнях, актуализируя широкий спектр вопросов: экология, потребление, производство, строительство, технологические инновации, ло- гистика и другие.

Наиболее популярным вопросом в последние пять лет является макроэкономическое осмысление национальных систем обращения вторичного сырья (Hao S., и др. [3]; Jaeger B., Upadhyay A. [4]; Hanumante N.C. и др. [5]; Kerdlap Р. и др. [6]; Sehnem, S. и др. [7]; Jeyanthan G., Ilankumaran G. [8]; [9] и др.). Неоднозначность субъектной принадлежности стейкхолдеров, бенефициаров системы вторичного обращения актуализирует научный поиск институциональных отношений (Angioletti C.M. и др. [10]); Linganiso, L.Z., Motaung, T.E.- концепция «Waste-to-Profit» $(\mathrm{W}-\mathrm{t}-\mathrm{P})[11])$.

На микроуровне реализуется научный поиск экономической эффективности субъектов обращения вторичного сырья, а на мезоуровне - мультипликативные эффекты: Velenturf A.P.M. и др. [12]; Mayer А. и др. [13]; Reuter M.А. и др. 
[14]. Региональные и отраслевые (по видам вторичного сырья) исследования дополняют видение общей системы обращения. Конъюнктуру, формирование рынков вторичного сырья рассматривали Волкова А.В. [15], Цимбал В.Д. [16], Калинина А.Э., Баракова А.С. [17] и др. А специфика отдельных отраслей - генераторов вторичного сырья рассмотрена: металлургия - Романов П. С. и др. [18], Сафонов М. С., Сенашов С.И. [19], Saidani М. и др. [20], Sellitto M. A., Almeida F. A. [21]; строительство - Глоба С.Б., Федоров М.И. [22], Pacheco-Torgal F. [23] и др. Важнейшим направлением научного поиска сохраняется вопрос экономически эффективных инновационных технологий обращения, в первую очередь переработки (Дадашев М.Н. и др. [24], Мирзаянов Ф.Ф. [25], Картамышева Е.С. [26], Wang М. и др. [27] и другие).

Обобщая взгляд на состояние современной дискуссии об экономике (микро- и мезо-) вторичного обращения авторы выделяют ее ключевой вопрос: дилемма об институциональной принадлежности, стейкхолдеров системы. Экологическая функция противопоставляется рыночной, предпринимательской природе обращения вторичных ресурсов. То есть, сохраняет актуальность вопрос: имеется ли самостоятельная экономическая целесообразность частного инвестиционного решения в отношении субъектов вторичной переработки или это государственная (частно-государственная) природоохранная функция.

Участие авторов в обозначенной научной дискуссии сфокусировано на вопросе экономической эффективности субъекта: промышленность переработки вторичного сырья. Публикации авторов [28], сформулированные в рамках гранта Waste Management SE 500 (2011-2014 год), инициировали научный диалог о балансе экономических факторов промышленности пере- работки вторичного сырья. Вышеприведённая научная дискуссия (2014-2020 года) и объективные тенденции изменения институциональной системы, конъюнктуры рынков обращения вторичного сырья [29], актуализировали вопрос экономической эффективности субъектов переработки. А в практическом видении авторы обнаруживают методические проблемы инвестиционного планирования [30], выраженные, в первую очередь, в неоднозначности экономической модели операционной деятельности субъектов переработки. В частности, у инвесторов нет объективной и прозрачной модели капиталовложений в проекты переработки вторичного сырья, что сдерживает приток частного капитала в отрасль.

Научные исследования авторов (2014-2020 года), опираясь на актуальные данные и эксперименты, позволили формализовать модель экономического баланса промышленного предприятия переработки вторичного сырья. В логистической, ресурсной форме модель отражена на рис. 1, а в эконометрической - ур. 1-3.

Модель выражает баланс ключевых входящих и исходящих потоков операционной деятельности в рамках целевых показателей: результативности - операционный доход и эффективности - рентабельность предприятия. Эконометрическая форма баланса промышленного предприятия переработки вторичного сырья раскрывается в трех уравнениях:

$$
\begin{aligned}
& \text { OperR }=Q_{C} \times\left(p_{c}+\gamma_{B}-D C\right)-Q_{A} \times p_{A} \quad, ; \\
& \text { Prof }=\text { OperR }-O C, \quad 2 ; \\
& \text { Prof } M=\text { Prof } \div \text { OperR, } 3 ;
\end{aligned}
$$

где: OperR - операционный доход, фин. ед.; Prof - прибыль, фин. ед.; ProfM - рентабельность,\%; $Q_{c}$ - объем произведенного и реализованного потребителям продукта из вторич-

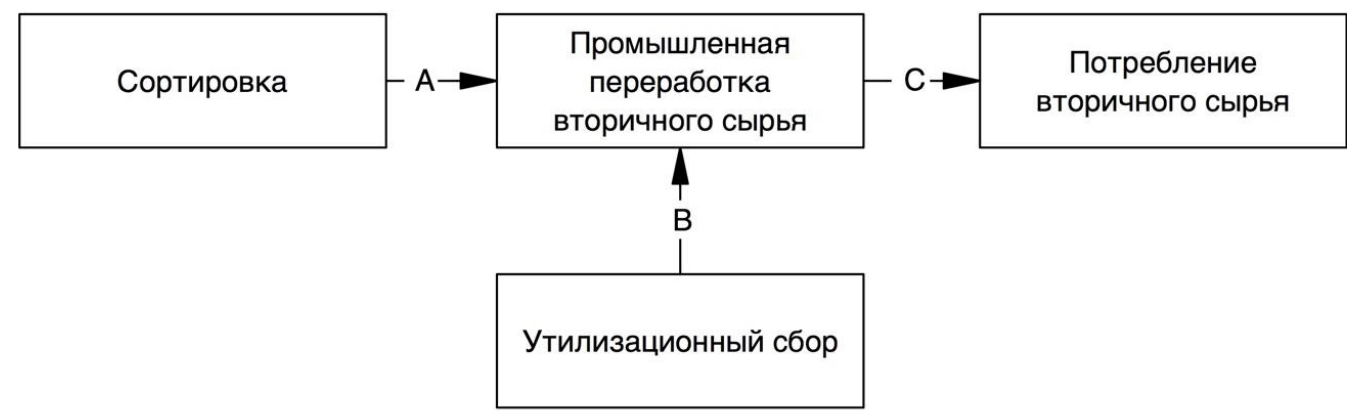

Puc. 1. Экономический баланс входящих и исходящих потоков промышленного предприятия переработки вторичного сырья. 
ного сырья, нат. ед.; $p_{c}-$ удельная рыночная стоимость произведенного и реализованного потребителям продукта из вторичного сырья, цена за нат. ед.; $\gamma_{B}-$ утилизационный сбор, поступивший промышленному предприятию за переработку вторичного сырья,\%.; $Q_{A}$ - объем закупленного вторичного сырья (отходов производства и пот ребления), нат. ед.; $p_{A}-$ удельная рыночная стоимость закупленного промышленным предприятием вторичного сырья, цена за нат. ед.; $D C$ - удельные прямые производственные расходы на переработку $\left(Q_{c}\right)$ вторичного сырья, фин. ед. за нат. ед.; ОС - внепроизводственные расходы, фин. ед.

Принимая ситуационно обусловленным фактор объема, размерности потоков вторичного сырья (региональное размещение и отраслевая принадлежность центров генерации) ядром модели принимается рентабельность, выражающая эффективность операционной деятельности субъектов переработки. Что позволяет сформулировать факторы баланса экономической эффективности промышленного предприятия переработки вторичного сырья, табл. 1.

Изучение факторов баланса является актуальной научной и практической задачей на настоящем этапе научной дискуссии об институциональной принадлежности вторичного обращения. Первичный вопрос которой авторы формулируют как оценка экономической эффективности операционной деятельности промышленных предприятий по переработке вторичного сырья.

\section{Цель исследования}

Выраженная в научной дискуссии неоднозначность оценок операционной эффективности процесса переработки вторичных ресурсов построена на позиции приоритетности, первичности экологической, природоохранной функции перерабатывающих предприятий. Ставится вопрос о рыночной самостоятельности, пред- принимательской природе самой модели вторичного обращения.

Соответственно, формулируется цель исследовать сложившиеся (актуальные) экономические характеристики операционной деятельности субъектов переработки вторичных ресурсов, что позволит ответить на принципиальный вопрос о возможности построения отрасли на рыночных, предпринимательских принципах. Характеристиками определяются показатель экономического масштаба - операционный доход (OperR, фин. ед.) промышленного предприятия переработки вторичного сырья, а эффекта - его рентабельность (ProfM, \%).

\section{Метод}

Методически поставленная цель реализована через статистический эксперимент, построенный на обследовании ключевых финансовых показателей отрасли вторичной переработки. Отрасль классифицируется российским ОКВЭД как «деятельность по обработке вторичного сырья» (38.3) и по структуре сопоставима с европейским отнесением по NACE Rev.2 (3832 Recovery of sorted materials). Выборка сформирована по данным пан-европейской базы данных Amadeus (https://amadeus.bvdinfo.com). Авторами включены в выборку предприятия с операционным доходом $\geqslant 500$, полагая (подтверждено кейс методом), что предприятия с более низким уровнем оборота находятся на инвестиционной стадии проекта. Численность выборки составила 4760 пан-европейских предприятий переработки вторичного сырья, включая 1237 российских субъектов отрасли.

По предприятиям выборки выделены ключевые годовые финансовые показатели 2018-2019 года (последний доступный период отчетности). Что позволило построить карту распределения операционного дохода и рентабельности.

Далее кейс методом (анализ хозяйственной деятельности предприятий) выделены квадран-

Таблица 1. Факторы баланса экономической эффективности промышленного предприятия переработки вторичного сырья.

\begin{tabular}{|l|l|}
\hline Перем. & Балансирующий фактор \\
\hline$Q_{C}$ & Размер кванта поставки вторичного сырья. \\
\hline$Q_{A}$ & Размер кванта закупки вторичного сырья. \\
\hline$p_{C}$ & Конъюнктура рынка вторичного сырья. \\
\hline$p_{A}$ & Конъюнктура рынка первичных отсортированных отходов. \\
\hline$\gamma_{B}$ & Нормативный утилизационный сбор по виду первичной продукции. \\
\hline$D C$ & Инновационность, эффективность технологии переработки. \\
\hline
\end{tabular}


ты, дифференцирующие группы предприятий по эффективности, технологическому уровню и типу вторичного сырья.

\section{Результаты}

Представленное поле (рис. 2) распределения показателей операционного дохода (OperR) и рентабельности (ProfM) в выборке обнаруживает 4 квадранта (А-С), с границами нулевой рентабельности и 50 млн. евро оборота.

Обоснованность выделения квадрантов демонстрируется дифференциацией баланса ресурсных факторов, уровня технологий и типов вторичного сырья, обнаруживаемых автором при обследовании (кейс-метод) отдельных предприятий. Баланс логистических, ресурсных факторов определяется вариативностью квантов (размер партии сырья), логистической удалённостью центров генерации сырья и конъюнктурой рынков. Технологическая эффективность определяется уровнем инновационного развития производственного процесса, специализацией или комбинированием оборудования процесса переработки. Что в высокой степени определяется типом вторичного сырья и степенью его фракционной чистоты (см. например, технологии переработки упаковки тетра-пак [31]).
Таким образом, нашла подтверждение авторская гипотеза о дифференциации экономической эффективности предприятий вторичной переработки с позиции вариативности баланса ресурсных факторов (рис. 1), актуального уровня развития технологий и состава вторичного сырья.

\section{Обсуждение}

Квадрант А отражает наиболее эффективную зону предпринимательства в силу оптимального баланса ресурсных факторов стоимости и объема, конъюнктуры и квантов вторичного сырья, нормативной величины утилизационного сбора. Технология переработки (в большинстве случаев) специализированная, а вторичное сырье однородное (не смешанное), с высоким содержанием легко- выделяемых фракций. Важно отметить, что выделение национальных (региональных) проекций в пан-европейской выборке демонстрирует аналогичное поле распределения финансовых показателей (сравним общую картину на рис. 2 и российский сегмент в выборке - рис. 3).

Средние значения индекса независимости капитала (BvD Independence Indicator) предприятий в квадранте А находятся в диапазоне А+ - B. Что свидетельствует о значимой доле частного

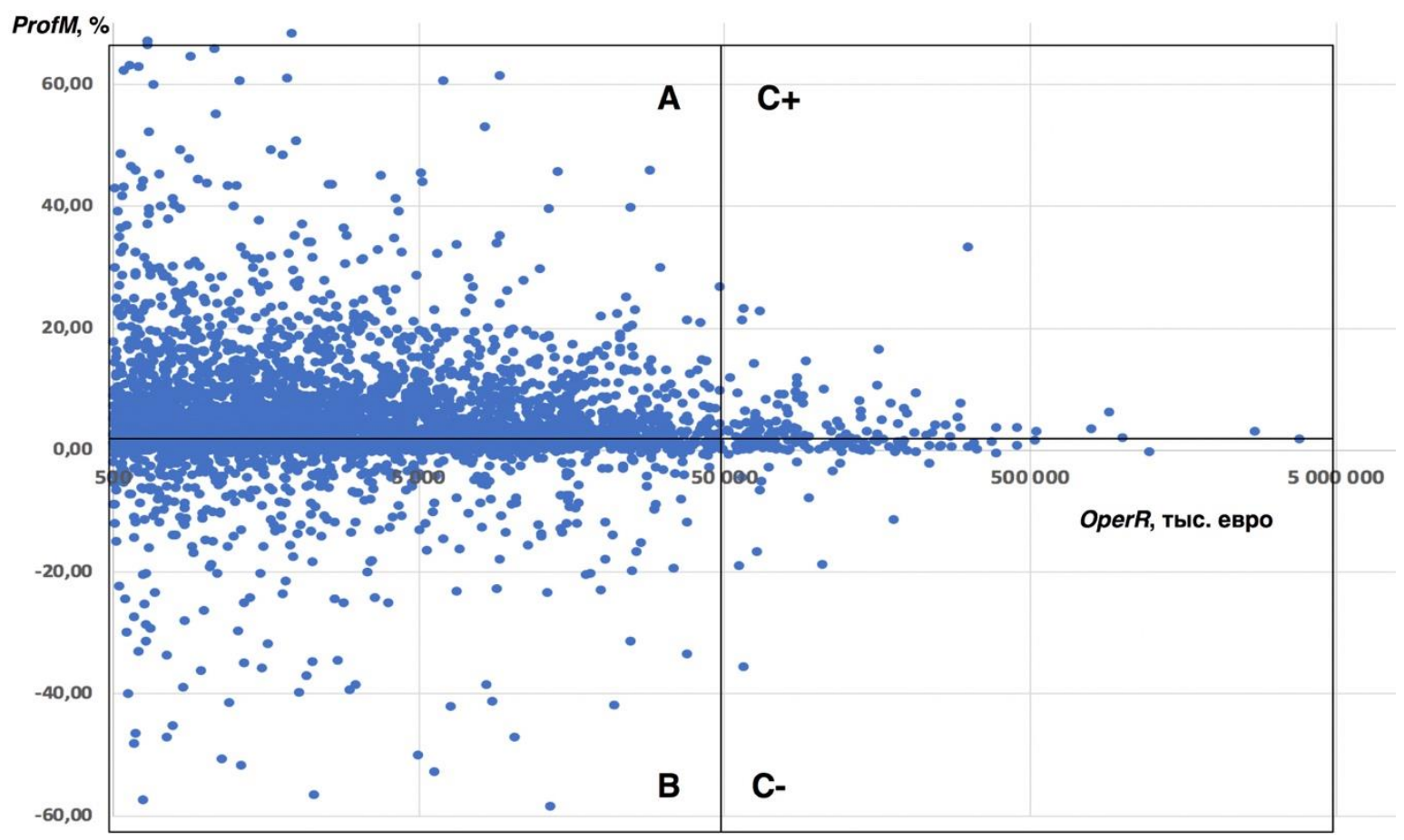

Puc. 2. Поле распределения показателей операционного дохода (OperR) и рентабельности (ProfM) предприятий переработки вторичных ресурсов в выборке. Описание квадрантов А-С в табл. 2. 
Таблица 2. Квадранты поля распределения (рис. 2).

\begin{tabular}{|c|c|c|c|}
\hline \multicolumn{2}{|r|}{ Квадрант } & Технологии & Вторичное сырье \\
\hline A & $\begin{array}{l}\text { Наиболее эффективный баланс } \\
\text { стоимости и объема сырья, } \\
\text { конъюнктуры и квантов (партий) } \\
\text { вторичного сырья, нормативных } \\
\text { тарифов на утилизацию. }\end{array}$ & $\begin{array}{l}\text { Развиты технологии (процесс- } \\
\text { ные инновации) промышленной, } \\
\text { обеспечивающие экономиче- } \\
\text { скую эффективность переработ- } \\
\text { ки. }\end{array}$ & Стекло; макулатура; металл и др. \\
\hline $\mathrm{B}$ & $\begin{array}{l}\text { Экономика депрессирована } \\
\text { одним или несколькими факто- } \\
\text { рами: квант сырья, конъюнктура } \\
\text { вторичного рынка или техноло- } \\
\text { гии. }\end{array}$ & $\begin{array}{l}\text { Не развиты технологии: высокая } \\
\text { трудоемкость переработки и(и- } \\
\text { ли) комбинирование различных } \\
\text { технологий. }\end{array}$ & $\begin{array}{l}\text { Бытовая техника и электроника; } \\
\text { деревянная упаковка; шин и др. }\end{array}$ \\
\hline $\mathrm{C}+$ & $\begin{array}{l}\text { Наиболее масштабные рынки } \\
\text { сырья, при различных по эф- } \\
\text { фективности квантах поставок и } \\
\text { технологий. }\end{array}$ & $\begin{array}{l}\text { Низкотехнологичное произ- } \\
\text { водство, эффект достигается } \\
\text { большими квантами поставок, } \\
\text { возможностью смешанного } \\
\text { использования первичного и } \\
\text { вторичного сырья. }\end{array}$ & $\begin{array}{l}\text { Металл; транспортные средства; } \\
\text { отходы добывающей и металлур- } \\
\text { гической промышленности и др. }\end{array}$ \\
\hline C- & & $\begin{array}{l}\text { Комбинированные техноло- } \\
\text { гии переработки в силу мульти } \\
\text { фракционности исходного сырья } \\
\text { (отходов). }\end{array}$ & $\begin{array}{l}\text { Упаковка напитков; пластик; } \\
\text { строительные отходы и др. }\end{array}$ \\
\hline
\end{tabular}

\section{ProfM, \%}

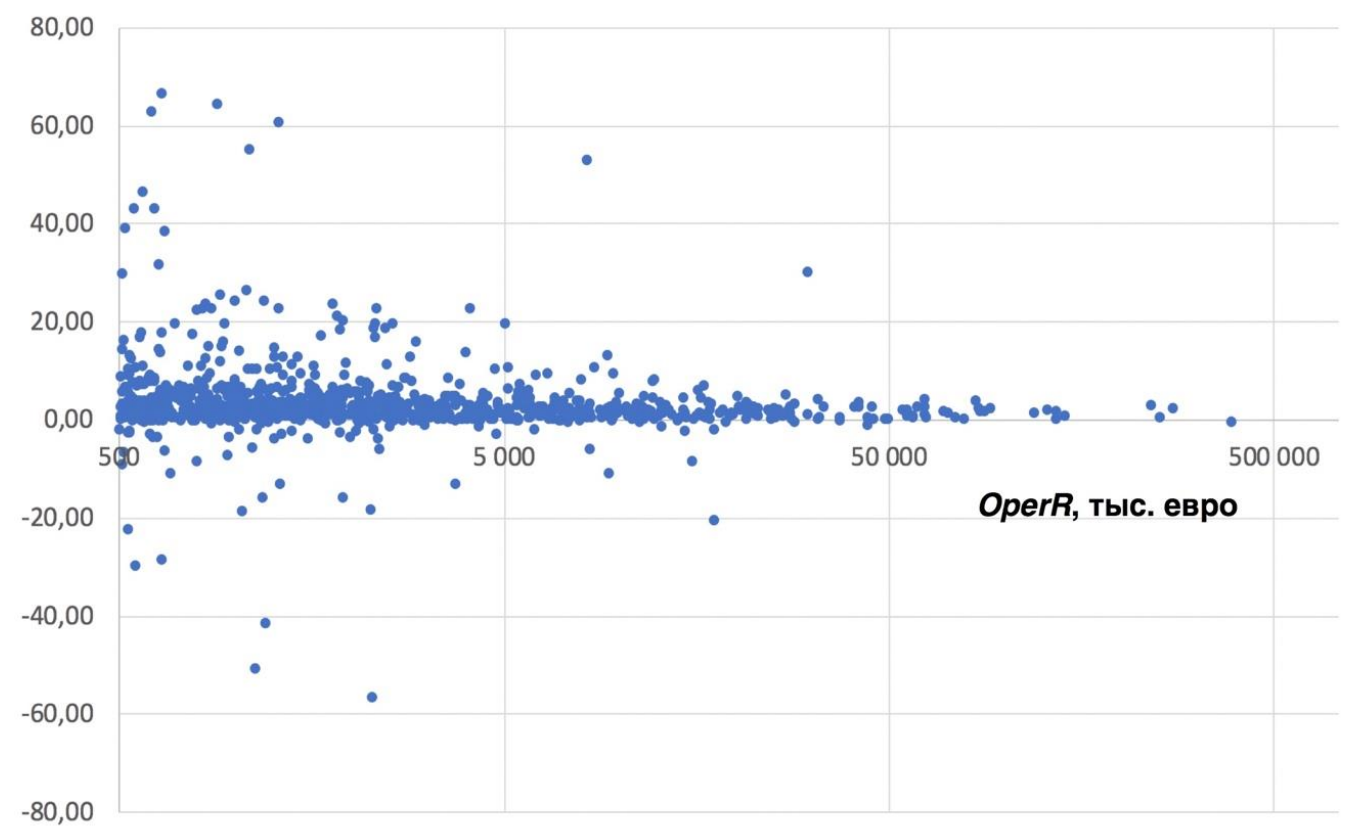

Puc. 3. Поле распределения показателей операционного дохода (OperR) и рентабельности (ProfM) предприятий переработки вторичных ресурсов в российском сегменте выборки. 
капитала, развитой предпринимательской активности, удовлетворенности инвесторов уровнем операционной рентабельности.

Предприятия квадранта А выделяются и с позиции технологической производственной эффективности. Процесс переработки 1-2 этапный с высокой степенью автоматизации и низким уровнем «ручной» переработки. О последнем свидетельствует, во-первых, отнесение квадранта А к зоне наименьшей трудоемкости 0,1-10\% (доля затрат на оплату труда в операционном обороте, переменная CostE/OperR), рис. 4. А во-вторых, высокой величины основных производственных фондов (TAss), указывающих на фондоемкость основного производственного процесса - переработка вторичного сырья, рис. 5.

Таким образом, квадрант А по балансу экономических факторов, производственному процессу и виду сырья выражает группу субъектов вторичной переработки, основанную на экономической выгоде инвестора (бенефициара).

В рамках обсуждаемой дилеммы это группа объективного предпринимательства, имеющая значительный потенциал частного инвестирования.

Изучение кейсов показало, что экономика предприятий в квадранте В и С- депрессирова- на одним или несколькими факторами: квант сырья, конъюнктура рынка вторичного сырья. Как правило, технологии не развиты: высокая трудоемкость переработки (рис. 4) и(или) совмещение различных технологических циклов (комбинирование). Предприятия поддержаны относительно большой величиной утилизационного сбора, а основная стратегия экономического развития направлена на увеличение квантов поставки и переработки (эффект масштаба) или приближения к центрам генерации вторичного сырья (кластеры). То есть в рамках данного квадранта бенефициаром является государство, реализующее экологическую, природоохранную функцию, что демонстрируется также высокой долей акционерного участия государства в группах В и С-.

Реализация стратегии роста объема входящего сырья $\left(Q_{c}\right)$ позволит им перейти в квадрант C+ с относительно высоким уровнем операционного дохода, но невысоким уровнем рентабельности, депрессированной низким развитием (или комбинированием) технологий. Экономическая эффективность C+ также обусловлена технологической возможностью смешения первичного и вторичного сырья (например, в металлургической переработке, см. кейс [18]).

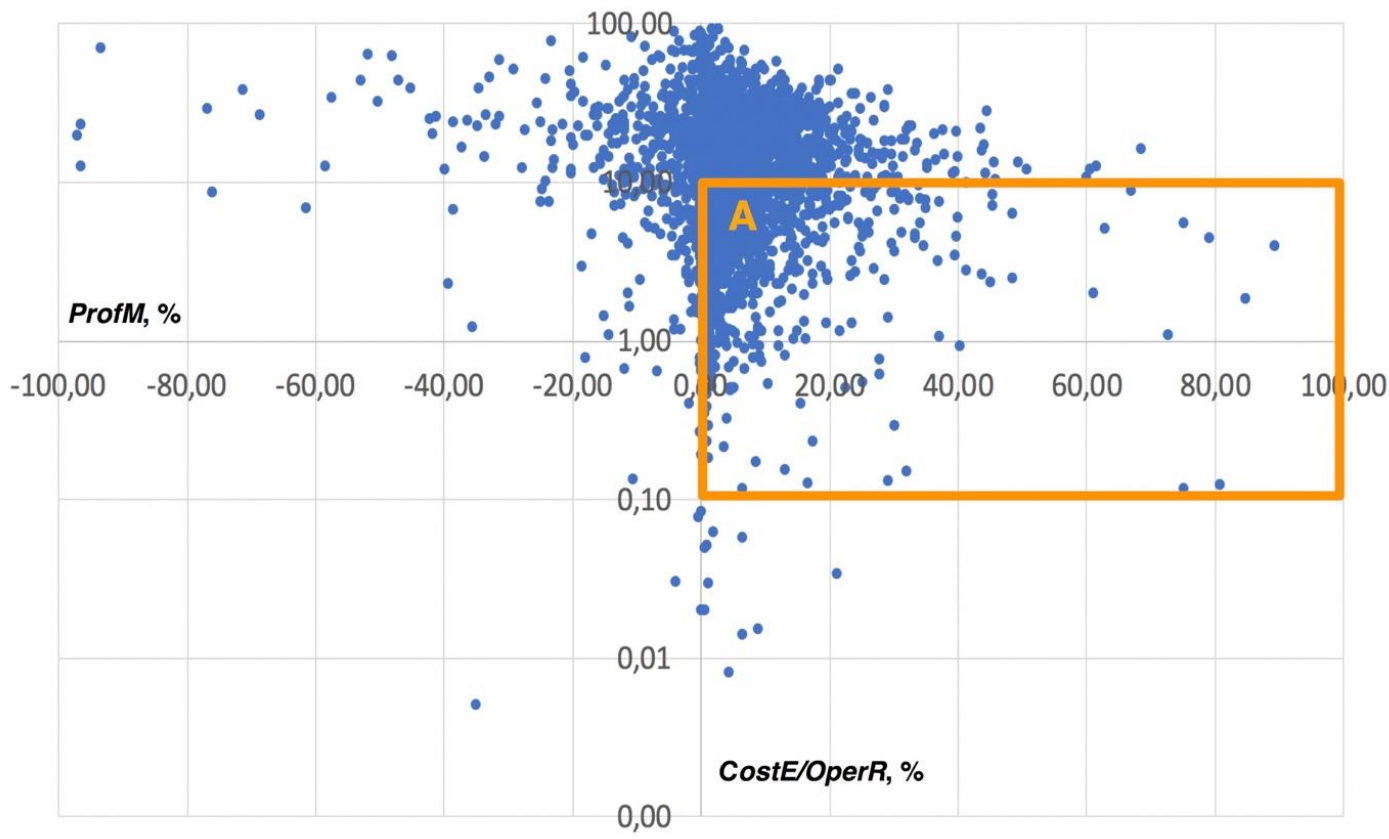

Puc. 4. Поле распределения показателей рентабельности (ProfM) и доли затрат на оплату труда в операционном обороте (CostE/OperR) предприятий переработки вторичных ресурсов в выборке. 


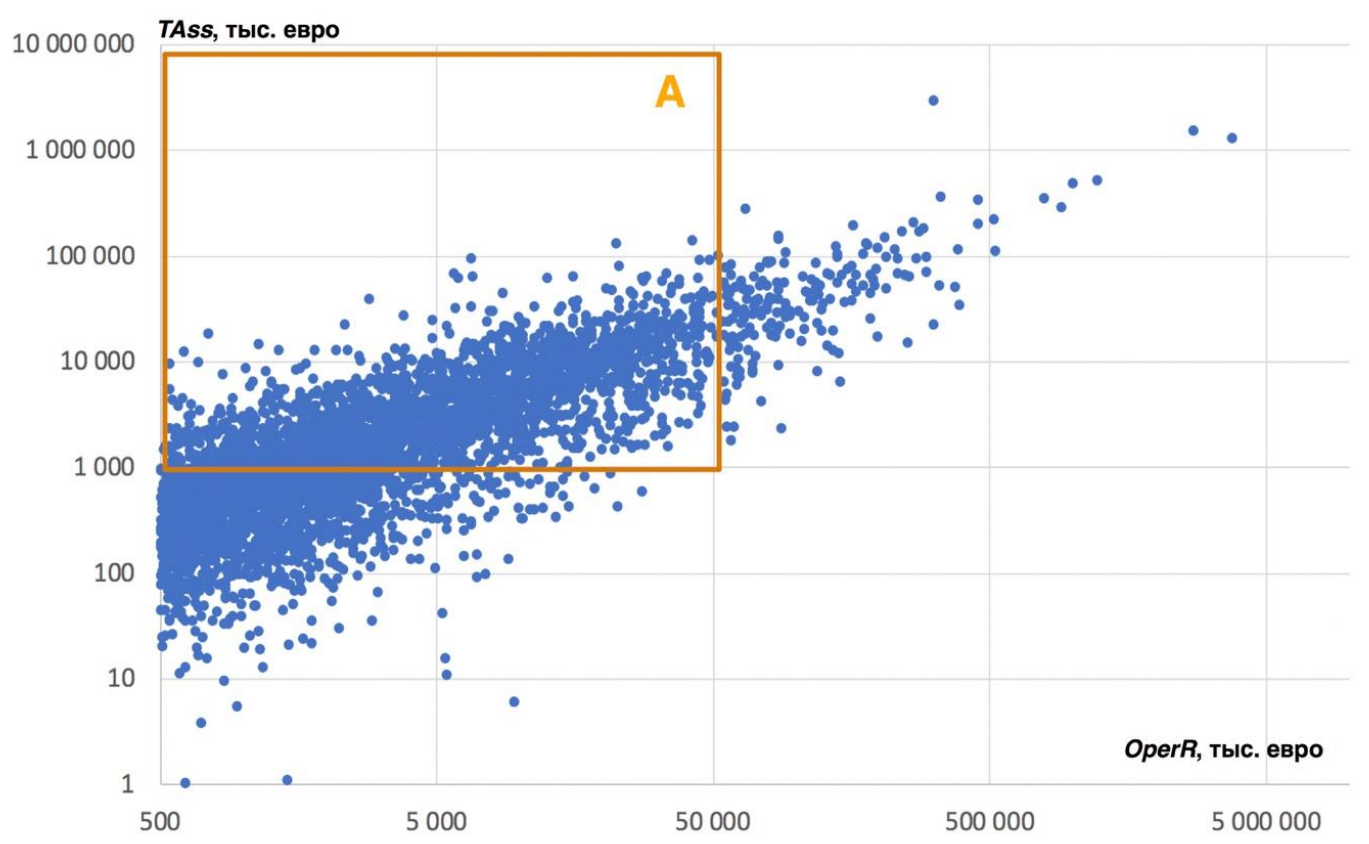

Puc. 5. Поле распределения показателей операционного дохода (OperR) и величины основных производственных фондов (TAss) предприятий переработки вторичных ресурсов в выборке.

\section{Заключение}

В рамках обсуждаемой дилеммы о стейкхолдерах системы вторичного обращения, авторами обнаруживается:

1. Рост инвестиционной привлекательности промышленности вторичной переработки, при наличии эффективного баланса экономических факторов: однородность сырья, низкая трудоемкость и высокий уровень развития технологии производства. Бенефициаром которой является частный инвестор;

2. Сохранение роли государства как бенефициара в низкотехнологичной, трудоемкой переработке неоднородного сырья, реализующего природоохранную функцию. Рост экономической, инвестиционной привлекательности зоны обусловлен развитием инновационных технологий переработки, снижающих трудоемкость (при объективной неизменности локализации центров генерации сырья и квантов поставок).
В практической плоскости авторское предложение формулируется как необходимость увеличения финансирования НИОКР в сфере вторичной переработки с фокусом на трудоемкие низкотехнологичные производства (квадранты В - С). Отсутствие таковых является сдерживающим фактором экономического развития, инвестиционной привлекательности для частного капитала.

А в качестве направления дальнейшего научного исследования авторы видят необходимость поиска оптимального экономического баланса (ур. 1-3, табл. 1) предприятий переработки вторичного сырья методом регрессионного анализа экономических пропорций в выборке. Решение данной задачи позволит выявить оптимальную экономическую модель формирования новых (или реструктуризации) предприятий отрасли.

\section{Библиографический список}

1. К экономике замкнутого цикла - инновационная политика в интересах устой-чивого производства и потребления. Записка секретариата Европейской эко-номической комиссии Комитета по инновационной деятельности, конкурен-тоспособности и государственно-частным партнерствам. Двенадцатая сессия. Женева, 26-28 марта 2018 года. Электронный документ. Режим доступа: https://www.unece.org/fileadmin/DAM/ ceci/documents/2018/CICPPP/Official_documents/ECE_CECI_2018_3_1802056R.pdf 18.05.2020.

2. Proost, J. Circular economy: The need to reuse resources. Maritime by Holland, 66 (2), 2017, pp. 26-28. 
3. Hao, S., Kuah, A.T.H., Rudd, C.D., Wong, K.H., Lai, N.Y.G., Mao, J., Liu, X. A circular economy approach to green energy: Wind turbine, waste, and material re-covery. Science of the Total Environment, 702, 2020.

4. Jaeger, B., Upadhyay, A.Understanding barriers to circular economy: cases from the manufacturing industry. Journal of Enterprise Information Management, 2020.

5. Hanumante, N.C., Shastri, Y., Hoadley, A. Assessment of circular economy for global sustainability using an integrated model. Resources, Conservation and Re-cycling, 151, 2019.

6. Kerdlap P., Low J.S.C., Ramakrishna S. Zero waste manufacturing: A framework and review of technology, research, and implementation barriers for enabling a circular economy transition in Singapore. Resources, Conservation and Recy-cling, 2019.

7. Sehnem, S., Vazquez-Brust, D., Pereira, S.C.F., Campos, L.M.S. Circular economy: benefits, impacts and overlapping. Supply Chain Management, 24 (6), 2019, pp. 784-804.

8. Jeyanthan, G., Ilankumaran, G. Circular economy - Key for the change of natural resource from scarce to abundance. International Journal of Recent Technology and Engineering, 8 (2 Special Issue 6), 2019, pp. 666-671.

9. Системы управления бытовыми отходами разных стран: Рецепты для России. Институт экономики роста им. Столыпина П.А. 2018. Электронный документ. Режим доступа: http://stolypin.institute/wp-content/ uploads/2019/10/sistemy-utilizatsii-othodov-raznyh-stran-25-09-2019.pdf 18.05.2020.

10. Angioletti, C.M., Despeisse, M., Rocca, R. Product circularity assessment method-ology. IFIP Advances in Information and Communication Technology, 514, 2017, pp. 411-418.

11. Linganiso, L.Z., Motaung, T.E. «Waste-to-Profit» (W-t-P): Circular economy in the construction industry for a sustainable future «Waste-to-Profit» (W-t-P): Circular Economy in the Construction Industry for a Sustainable Future, 2, 2019, pp. 1-356.

12. Velenturf, A.P.M., Jopson, J.S. Making the business case for resource recovery. Science of the Total Environment, 648, 2019, pp. 1031-1041.

13. Mayer, A., Haas, W., Wiedenhofer, D., Krausmann, F., Nuss, P., Blengini, G.A. Measuring Progress towards a Circular Economy: A Monitoring Framework for Economy-wide Material Loop Closing in the EU28. Journal of Industrial Ecology, 23 (1), 2019, pp. 62-76.

14. Reuter, M.A., Van Schaik, A., Gutzmer, J., Bartie, N., Abadías-Llamas, A. Chal-lenges of the Circular Economy: A Material, Metallurgical, and Product Design Perspective. Annual Review of Materials Research, 49, 2019, pp. 253274.

15. Волкова А.В. Рынок утилизации отходов-2018. ВШЭ, 2018. Электронный до-кумент. Режим доступа: https:// dcenter.hse.ru/data/2018/07/11/1151608260/Рынок\%20утилизации\%20отходов\%202018.pdf 7.05.2020.

16. Цимбал В.Д.Утилизация и методы переработки твердых бытовых отходов. В сборнике: Внедрение результатов инновационных разработок: проблемы и перспективы. сборник статей Международной научнопрактической конфе-ренции: в 3 частях. 2017. С. 97-100.

17. Калинина А.Э., Баракова А.С. Анализ мирового опыта обращения с бытовыми отходами. Вестник Волгоградского государственного университета. Серия 3: Экономика. Экология. 2018. Т. 20. № 3. С. 120-125.

18. Романов П.С., Романова И. П. Рециклинг отходов металлургической промыш-ленности как способ сбережения природных ресурсов и снижения экологиче-ской напряженности. Синергия. 2016. № 2. С. 94-99.

19. Сафонов М.С., Сенашов С.И. Управление комплексом по реализации и пере-работке металлолома. Современные проблемы экономического и социально-го развития. 2015. № 11. С. 40-43.

20. Saidani, M., Yannou, B., Leroy, Y., Cluzel, F. Dismantling, remanufacturing and recovering heavy vehicles in a circular economy - Technico-economic and or-ganisational lessons learnt from an industrial pilot study. Resources, Conserva-tion and Recycling, 156, 2020.

21. Sellitto, M.A., Almeida, F. A. Strategies for value recovery from industrial waste: case studies of six industries from Brazil. Benchmarking, 27 (2), 2019, pp. 867-885.

22. Глоба С.Б., Федоров М. И. Исследование экономических факторов развития строительного рециклинга. Бизнес. Образование. Право. 2019. № 2 (47). С. 104-108.

23. Pacheco-Torgal, F. Handbook of recycled concrete and demolition waste / F.Pacheco-Torgal, J. de Brito, J. Labrincha. - Australia: University of Western Syd-ney, 2013. - 646 p.

24. Дадашев М.Н., Бабаев С. Н., Крупнов В.А. Новый подход к безопасной утили-зации отходов перерабатывающих и добывающих отраслей промышленности. В сборнике: Мелиорация почв для устойчивого развития сельского хозяйства Материалы Международной научно-практической конференции, посвящён-ной 100-летию со дня рождения профессора Александра Филипповича Тимо-феева. 2019. С. 65-68.

25. Мирзаянов Ф. Ф. Современные инновационные технологии и продукты про-мышленной переработки вторичных ресурсов. Фундаментальные исследова-ния. 2015. № 4. С. 224-228. 
26. Картамышева, Е. С. Новые технологии переработки отходов производства в современном мире / Е.С. Картамышева, Д. С. Иванченко. - Текст: непосред-ственный // Молодой ученый._ 2017. - № 51 (185). - С. 115118.

27. Wang, M., Liu, P., Gu, Z., Cheng, H., Li, X. A scientometric review of resource re-cycling industry. International Journal of Environmental Research and Public Health, 16 (23), 2019.

28. Алексеев А.А., Карлик А.Е., МахатадзеЛ.П. Развитие региональной системы управления отходами: опыт проекта SE500. Экономика и управление. 2013. № 4 (90). С. 12-18.

29. Алексеев А.А., Фомина Н.Е., ФоминЕ.П. Сценарное моделирование регио-нальных систем обращения с отходами: логистический, строительный, инве-стиционный, инновационный аспекты. Вестник Самарского государственного экономического университета. 2014. № 12 (122). С. 55-62.

30. Алексеев А.А.Переработка отходов - инновационный сегмент промышленно-сти. Известия СанктПетербургского государственного экономического уни-верситета. 2014. № 3 (87). С. 17-23.

31. Смоляков А.И., Клеванова Е. С. Перерабатываемый неперабатываемый TETRA РАК. Электронный документ. Режим доступа: https://www.solidwaste.ru/i/publ/1276/022-025.pdf 26.05.2020. 